CONGENITAL HEART DISEASE

\title{
Long term results of percutaneous balloon valvoplasty of congenital aortic stenosis: independent predictors of outcome
}

\author{
O Reich, P Tax, J Marek, V Rázek, J Gilík, V Tomek, V Chaloupecký, H Bartáková, J Škovránek
}

Heart 2004;90:70-76

See end of article for authors' affiliations

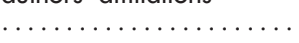

Correspondence to: DrO Reich,

Kardiocentrum, University Hospital Motol, $V$ úvalu

84, Prague 15006, Czech Republic; oleg.reich@ Ifmotol.cuni.cz

Accepted 18 July 2003

\begin{abstract}
Objective: To evaluate long term results and independent predictors of outcome of aortic valvoplasty. Design: Retrospective follow up study. Independent predictors of outcome identified by multiple logistic regression.

Setting: Tertiary referral centre.

Patients: 269 consecutive patients treated at the median age of 8 months (0-23 years): 80 (30\%) under 4 weeks, 59 (22\%) between 4 weeks and 1 year, and 130 (48\%) over 1 year. The follow up period was up to 14.8 years (median 5.3, in survivors 6.4 years).

Interventions: Percutaneous balloon valvoplasty with mean (SD) balloon to annulus ratio 0.97 (0.08).

Main outcome measures: Restenosis $\geqslant 70 \mathrm{~mm} \mathrm{Hg}$, grade 3 aortic insufficiency, cusps disruption, surgery, death, and valvoplasty failure (significant restenosis or insufficiency or surgery or death).

Results: The mortality rate was $10.4 \%(n=28)$, the restenosis rate was $16.7 \%(n=45)$, significant insufficiency developed in $22.3 \%(n=60)$, surgery was needed in $20.1 \%(n=54)$, and "valvoplasty failure" occurred in $41.6 \%$ ( $n=112$ ) patients. Mean (SEM) survival probability 14.4 years after the procedure was $0.89(0.02)$ and mean (SEM) probability of surgery-free survival was $0.50(0.08)$. The independent predictors were as follows. For restenosis: small aortic annulus; for cusp disruption: large aortic annulus; for insufficiency: bicuspid aortic valve; for need for surgery: bicuspid aortic valve; for death: small aortic annulus, low left ventricular shortening fraction, and low sequential number of the valvoplasty; and for valvoplasty failure: small aortic annulus, bicuspid aortic valve, and high grade of mitral insufficiency.

Conclusion: Independent predictors of unfavourable outcome are small aortic annulus, bicuspid aortic valve, poor function of left ventricle or mitral valve, and limited operator experience.
\end{abstract}

$\mathrm{P}$ ercutaneous balloon valvoplasty was first described in 1983. ${ }^{1}$ The effectiveness of the method in gradient reduction and the low incidence of restenosis shortly after the procedure were documented in children with congenital aortic stenosis. ${ }^{2}$ In 1986, the first balloon valvoplasty was performed in a newborn with critical aortic stenosis. ${ }^{3}$ Good short term results were obtained in a large cohort of children in a multicentre study. ${ }^{4}$ Mid-term results, however, showed a substantial incidence of restenosis, severe aortic insufficiency, and reinterventions. ${ }^{56}$ Long term results have so far been published only for children treated after 1 year of age with a $20 \%$ restenosis rate and a $21 \%$ incidence of significant aortic insufficiency $2-12$ years after the procedure. ${ }^{7}$

The purpose of our study was to evaluate long term results of percutaneous balloon valvoplasty of congenital aortic stenosis in a large cohort of newborns, infants, children, adolescents, and young adults, and to assess independent predictors of unfavourable outcome of the treatment.

\section{MATERIAL AND METHODS}

\section{Patients}

Since March 1987, percutaneous balloon valvoplasty has been used in our institution as the first choice method of treatment of aortic stenosis. The procedure was indicated in all the patients with Doppler peak gradient $\geqslant 70 \mathrm{~mm} \mathrm{Hg}$, in patients with left ventricular strain on the ECG and peak gradient of $\geqslant 60 \mathrm{~mm} \mathrm{Hg}$, and regardless of the gradient in all the patients presenting with syncope, cardiogenic shock, low cardiac output, severe left ventricular dysfunction, or duct dependent systemic circulation. Up to the end of 2002, a total of 269 consecutive patients were treated with valvoplasty and they all were included in this retrospective study.

The median age at the time of valvoplasty was 8 months (range $0-23$ years). There were 80 (30\%) newborns under 4 weeks of age, 59 (22\%) infants between 4 weeks and 1 year, and $130(48 \%)$ children, adolescents, and young adults over 1 year of age. Among the newborns, 65 (24\% of all the patients) required urgent treatment in their first week of life. Body weight at the time of the procedure ranged from $1.5-79 \mathrm{~kg}$ (median $8.4 \mathrm{~kg}$ ).

Aortic annulus diameter was subnormal on average (mean (SD) $\mathrm{z}$ score $-2.128(1.557))$. Hypoplasia was especially notable in newborns and the annulus diameter increased significantly with age at valvoplasty $(R=0.620$, SEE $=1.223, p<0.001) \quad($ fig 1$)$. The aortic valve was tricuspid in $86(32.0 \%)$, bicuspid in $145(53.9 \%)$, and unicuspid in 38 patients $(14.1 \%)$. In 124 patients with a bicuspid valve further differentiation into two anatomical subtypes was possible: anatomically bicuspid valve with only two sinuses of Valsalva and functionally bicuspid valve, which also opened as bicuspid but had three sinuses of Valsalva, two of them adjacent to a fused cusp formed by two unequally sized cusps conjoined by an unopened commissure. An anatomically bicuspid valve was present in 63 $(23.4 \%)$ and a functionally bicuspid valve in 61 patients $(22.7 \%)$. In 50 patients $(18.6 \%)$, a reverse diastolic doming of the aortic valve was present before the valvoplasty, but in only 16 with aortic insufficiency grade $\geqslant 1$. Aortic insufficiency grade $\geqslant 1$ was present in a further 34 patients (total 


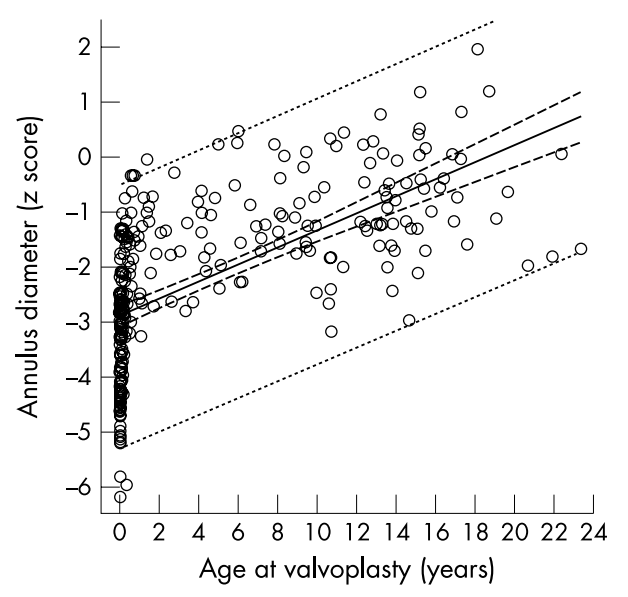

Figure 1 Regression of aortic annulus diameter (normal $z$ score) and age at valvoplasty. Annulus is $0.751+0.0000403 \times$ age in days, $R=0.620$, SEE $=1.223, \mathrm{p}<0.001$.

50 patients, $18.6 \%$ ). From newborns to the older patients, the proportion of unicuspid valves decreased in favour of tricuspid ones $(p<0.001)$. Reverse doming and aortic insufficiency before valvoplasty were significantly more frequent in patients over l year than in the other two groups (both $\mathrm{p}<0.001$ ) (table 1).

Endocardial fibroelastosis was detected in 37 (13.8\%), grade 3 mitral insufficiency in 26 (9.7\%), mitral stenosis in 21 $(7.8 \%)$, and coarctation of the aorta in 20 patients $(7.4 \%)$.

\section{Procedures}

All the patients had a complete clinical and ultrasound examination before the valvoplasty.

\section{Echocardiography}

Aortic valve gradient was assessed by continuous and pulsed Doppler from a subcostal, apical, jugular, and right subclavicular approach, and the highest gradient measured was accepted. Peak gradient was calculated from maximum flow velocity and mean gradient by a time-velocity integral. Aortic insufficiency was assessed by colour flow mapping and pulsed Doppler and scored on a four grade scale: grade 0 to 3 (0, no regurgitation; 1 , regurgitation without a reverse diastolic flow in the aortic arch; 2, reverse flow in the aortic arch but not in the abdominal aorta; and 3, reverse diastolic flow in the abdominal aorta). The diastolic dimension of the left ventricle, left ventricular shortening fraction, and left ventricular posterior wall thickness were measured with $M$ mode imaging. The aortic annulus diameter and the morphology of the aortic valve were assessed by means of two dimensional imaging from the parasternal long and short axis views. Laboratory specific normal values ${ }^{8}$ were used for comparison.

\section{Valvoplasty}

Informed consent to undergo the procedure was signed by parents or patients as appropriate. The valvoplasty was performed from the percutaneous femoral arterial approach in all but three patients. In two patients the procedure was performed progradely and in a preterm baby (1500 g) through a carotid artery cut down. There was almost perfect agreement between the echocardiography and aortography in the annulus diameter measurements $(R=0.978$, SEE $=1.533, \mathrm{p}<0.001)$. If, however, the diameters measured with the two methods differed, the smaller measure was taken as the reference. The chosen balloon diameter was preferably equal to or slightly less than the aortic valve annulus. However, if such a balloon did not reduce the gradient sufficiently and did not cause aortic insufficiency, a balloon with a $1 \mathrm{~mm}$ larger diameter was used. The resulting balloon to annulus diameter ratio ranged from 0.74 to 1.25 (mean (SD) $0.97(0.08)$ ). Mean (SD) fluoroscopy time was 18.8 (11.4) minutes.

\section{Follow up}

The patients were followed up by clinical examination and complete echocardiographic evaluation a day after the procedure, at discharge from hospital, a month after discharge, and later at six month to two year intervals according to the residual findings. The follow up period ranged from 30 days to 14.8 years (median 5.3 years, in survivors 6.4 years). Fourteen patients were lost to follow up. Another 28 patients were contacted only by mail or telephone and for eight of them, echocardiographic findings were obtained from their physicians. All others had a complete clinical and echocardiographic evaluation in our outpatient clinic. Thus, follow up data were available for 255 (94.8\%) patients and complete echocardiographic follow up data were available for 235 patients $(87.4 \%)$. In the patients lost to follow up the last available echocardiographic data were used for analyses, and in the patients who required surgery or died the last echocardiography before surgery or death were used.

\section{Statistical analysis}

The data sets were tested for normal distribution and for equal variance when they were compared. If the normal distribution and equal variance were proved, parametric tests were used (paired $t$ test, Pearson regression) and the data are displayed as mean (SD). Otherwise the data were compared by Friedman repeated measures analysis of variance and results are displayed as median (25th centile/75th centile). Differences in proportions were tested by the $\chi^{2}$ test. The Kaplan-Meier estimate was used to calculate actuarial probabilities and the Gehan-Breslow test (Holm-Sidak method) was used for their comparison. Independent predictors of outcome were identified by backwards multiple logistic regression with the limit of $p \leqslant 0.05$ for retaining the variables in the model. For logistic regression, continuous variables were standardised by replacing actual values by

Table 1 Anatomy of the aortic valve by age group

\begin{tabular}{lcccc}
\hline Aortic valve & $\begin{array}{l}\text { Newborns } \\
(\mathbf{n}=\mathbf{8 0})\end{array}$ & $\begin{array}{l}\text { Infants } \\
(\mathbf{n}=59)\end{array}$ & $\begin{array}{l}\text { Patients }>\mathbf{1} \text { year } \\
(\mathbf{n = 1 3 0 )}\end{array}$ & p Value \\
\hline Unicuspid & $27(33.75 \%)$ & $7(11.87 \%)$ & $4(3.08 \%)$ & \\
Anatomically bicuspid & $21(26.25 \%)$ & $17(28.81 \%)$ & $25(19.24 \%)$ & \\
Functionally bicuspid & $12(15.00 \%)$ & $17(28.81 \%)$ & $32(24.63 \%)$ & $<0.001$ \\
Bicuspid (unspecified) & $3(3.75 \%)$ & $4(6.78 \%)$ & $14(10.73 \%)$ & \\
Tricuspid & $17(21.25 \%)$ & $14(23.73 \%)$ & $55(42.32 \%)$ & \\
Aortic insufficiency & $5(6.25 \%)$ & $5(8.47 \%)$ & $40(30.76 \%)$ & $<0.001$ \\
Reverse doming & $9(11.25 \%)$ & $3(5.08 \%)$ & $44(33.85 \%)$ & $<0.001$ \\
\hline
\end{tabular}


Table 2 End points and variables tested by multiple logistic regression

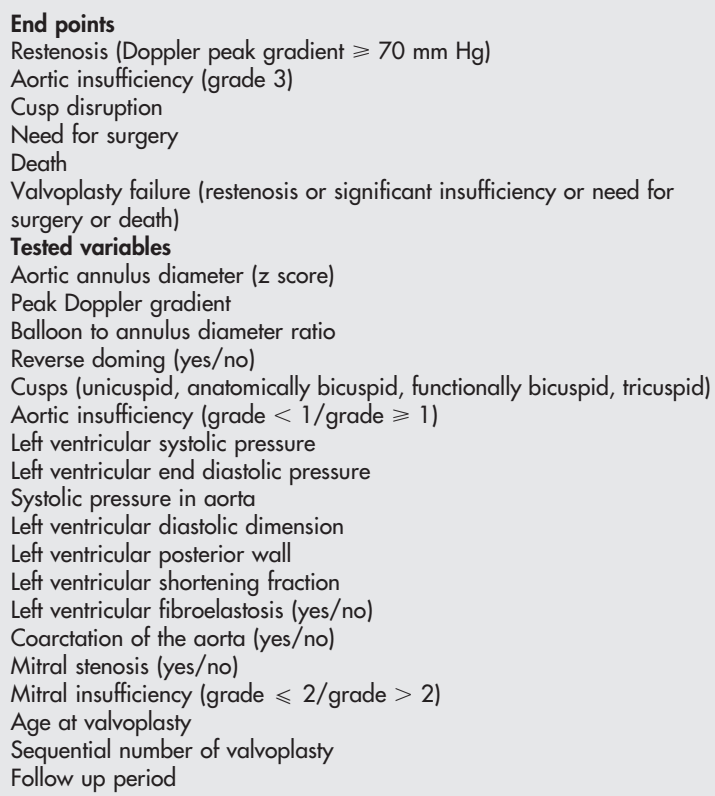

sample standard scores. Table 2 lists the end points and the tested variables. Restenosis, cusp disruption, aortic insufficiency, and need for surgery were tested only with the valve characteristics. Death and valvoplasty failure were tested with all the variables. Results with a probability value of $\mathrm{p}<0.05$ and in parametric tests with the test power of $>0.80$ were considered significant.

\section{RESULTS}

The vascular access complication rate was $1.5 \%$ : permanent pulse loss in three newborns and surgically treated iliac artery perforation in a premature baby. In the other five newborns, there was a transient pulse loss that was resolved by medical treatment. We had to abort the procedure because of vascular access problems in a $1500 \mathrm{~g}$ newborn in whom the iliac artery was perforated and the valvoplasty had to be performed later through a carotid artery cut down.

By valvoplasty, the catheter measured gradient was reduced from a mean (SD) of 78.3 (27.4) to 27.6 (16.2) $\mathrm{mm} \mathrm{Hg}(\mathrm{p}<0.001)$ and left ventricular pressure from $162.3(37.1)$ to $124.3(33.0) \mathrm{mm} \mathrm{Hg}(\mathrm{p}<0.001)$. Systolic aortic pressure rose from 81.9 (24.1) to 96.3 (26.4) $\mathrm{mm} \mathrm{Hg}$ $(\mathrm{p}<0.001)$. The Doppler peak gradient was reduced from a median (25th/75th centile) $80.0 \quad(64 / 95)$ to $41.5 \quad(32 /$ $55) \mathrm{mm} \mathrm{Hg}(p<0.001)$. The last follow up value of 45.0 (34/58) $\mathrm{mm} \mathrm{Hg}$ did not differ significantly from the postvalvoplasty peak gradient. Similar changes were observed in the Doppler mean gradient: 48.0 (38/57) mm Hg before the procedure, $23.0(17 / 31) \mathrm{mm} \mathrm{Hg}$ after the procedure $(\mathrm{p}<0.001)$, and $24.0(17 / 32) \mathrm{mm} \mathrm{Hg}$ at the latest follow up. The grade of aortic insufficiency increased from $0.0(0.0 /$ $0.0)$ to $1.0(0.0 / 2.0)$ with the valvoplasty and further to 2.0 $(1.0 / 2.5)$ at the latest follow up (all p $<0.001$ ) (fig 2).

Figure 3 shows details of the clinical outcome. A persistent good result (residual peak Doppler gradient $<70 \mathrm{~mm} \mathrm{Hg}$ and aortic insufficiency grade $<3$ ) was achieved in 145 patients $(53.9 \%)$, in 14 of them after a repeated valvoplasty. Another 12 patients (4.5\%) who have been lost to follow up had a good result documented early after the procedure. The gradient was not reduced sufficiently (early restenosis) in 19 patients but in 10 of them a good result was achieved by repeat valvoplasty. Recurrence of a peak gradient $\geqslant 70 \mathrm{~mm} \mathrm{Hg}$ (late restenosis) developed 21 days to 12.7 years (median 225 days) after valvoplasty in 33 patients, and in four of them the repeat valvoplasty provided a good result. In seven patients $(2.6 \%)$ a peak gradient $>70 \mathrm{~mm} \mathrm{Hg}$ along with grade 3 insufficiency developed during the follow up period. Thus, a restenosis untreatable with repeat valvoplasty was encountered in 45 patients $(16.7 \%)$. Grade 3 aortic insufficiency developed in 60 patients $(22.3 \%)$ including the seven patients with restenosis. In 20 of them the insufficiency was documented immediately after the valvoplasty and in 40 it developed 48 days to 13.7 years (median 4.2 years) after the procedure. The late insufficiency was caused in nine patients by repeat valvoplasty. Disruption or avulsion of an aortic valve cusp as a cause of the insufficiency was detectable by two dimensional echocardiography in 20 (7.4\%) patients.

During the follow up period, 102 aortic valve reinterventions (45 repeat valvoplasties and 57 operations) were
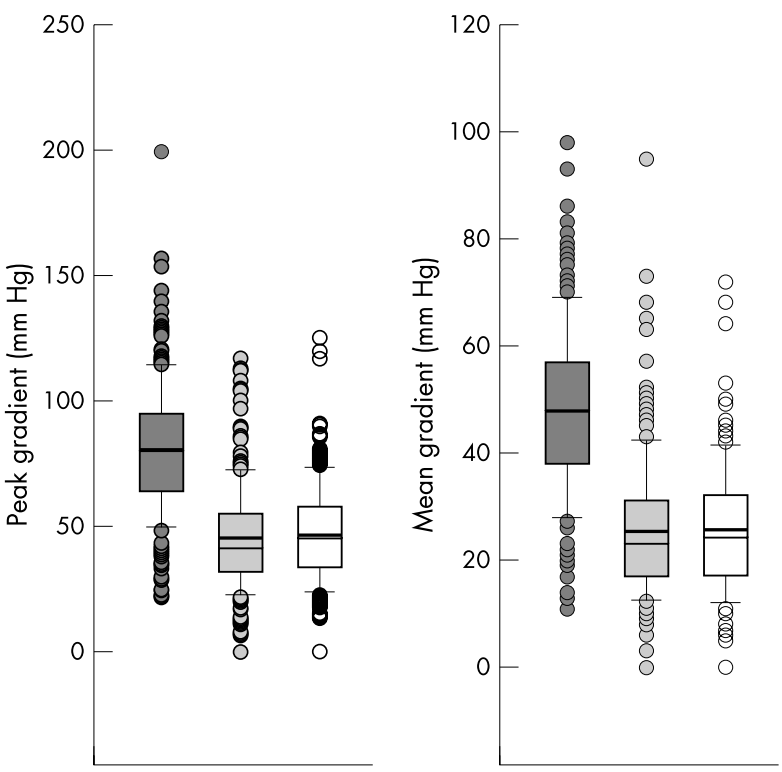

Figure 2 Comparison of Doppler peak and mean gradients and aortic insufficiency grade (from left to right) before the valvoplasty, a day after, and at the last follow up. Boxes indicate 25th and 75th centiles, error bars 10th and 90th centiles, and circles cases outside this interval. The thin lines within the boxes indicate medians and the thick lines means. 


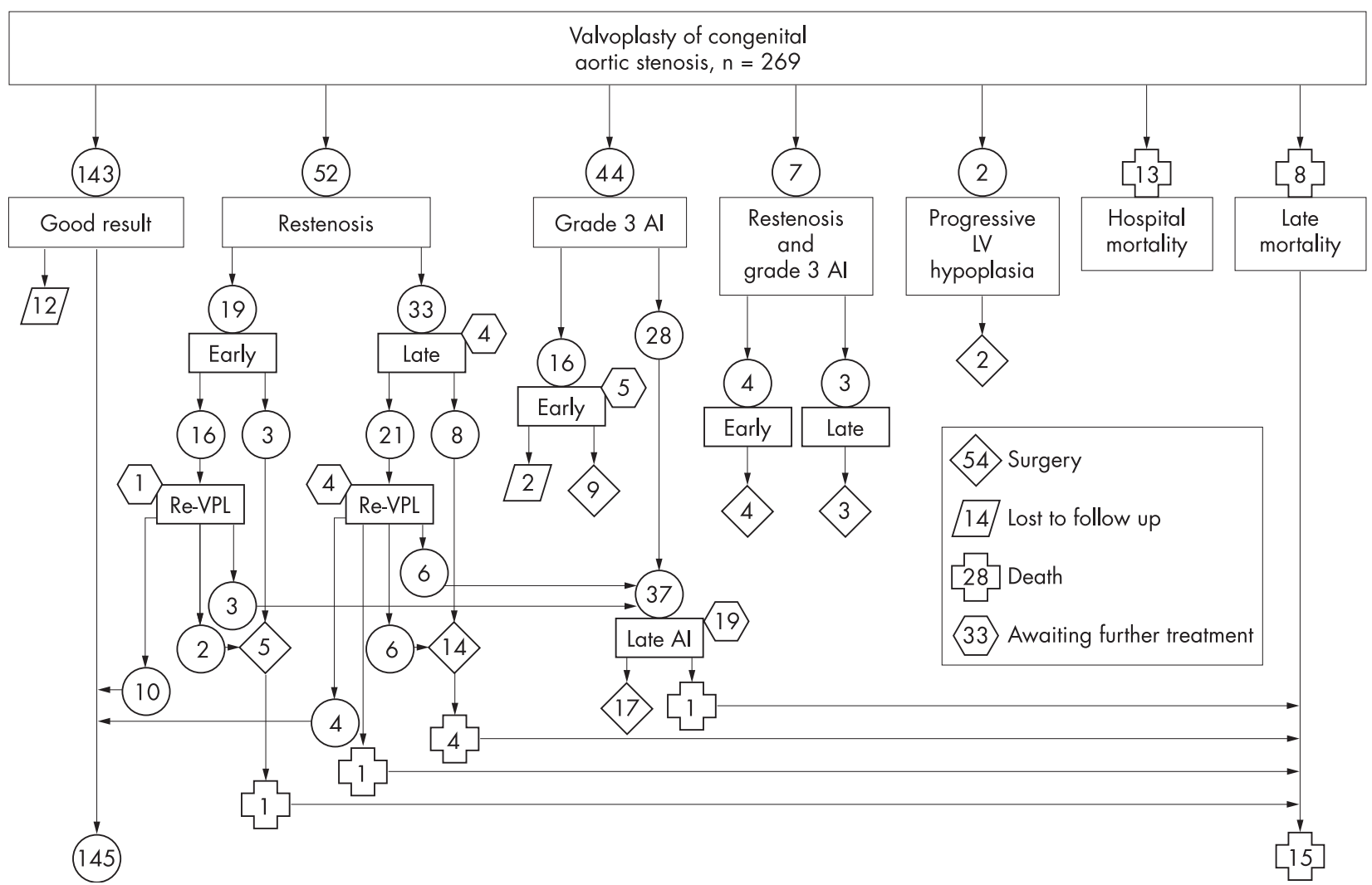

Figure 3 Clinical outcome. A good result was defined as a residual peak Doppler gradient $<70 \mathrm{~mm} \mathrm{Hg}$ and aortic insufficiency grade $<3$. Only the first repeat valvoplasty and/or the first surgery of the aortic valve is shown for each patient. Eight patients had an additional repeat valvoplasty and three patients had another aortic valve surgery. Al, aortic insufficiency; LV, left ventricle; Re-VPL, repeat valvoplasty.

performed in 78 patients $(29.0 \%)$. The cause of the initial reintervention was restenosis in $48(17.8 \%)$, restenosis along with significant regurgitation in $7(2.6 \%)$, and significant insufficiency in 21 patients $(7.8 \%)$. In two patients $(0.8 \%)$, initially borderline left ventricles did not grow sufficiently after the valvoplasty and they were palliated with a Norwood procedure. The initial reintervention was a repeat valvoplasty in 37 patients and surgery in 41 patients. In 13 patients whose restenosis was initially treated with the repeat valvoplasty, surgery was necessary, in five of them because of severe aortic insufficiency. Thus, surgery was needed in 54 patients $(20.1 \%)$. Thirty three patients with significant residual findings-five of them after repeat valvoplastyare awaiting further treatment.

A total of 28 patients ( $10.4 \%$ ) died of the aortic stenosis or in connection with its treatment. Procedure related hospital mortality was $4.8 \%$ ( 13 patients). Seven patients died of low cardiac output, two of left ventricular hypoplasia, one of a progressive mitral insufficiency, one of disseminated intravascular coagulation, one of Candida species sepsis, and one of a procedural complication (arterial duct rupture). Late mortality was $5.6 \%$ ( 15 patients). There were eight sudden deaths presumably caused by an arrhythmia, one patient died of left ventricular hypoplasia, and one of cardiac failure caused by severe aortic insufficiency. Five patients died after subsequent aortic valve surgery: four from low cardiac output, and one from mitral stenosis and insufficiency along with left ventricular hypoplasia. In the eight patients who died suddenly, the last peak gradient was $20-60 \mathrm{~mm} \mathrm{Hg}$ (mean $43 \mathrm{~mm} \mathrm{Hg}$ ) and aortic insufficiency was grade 0 to 2 (mean 1.1). Three other patients died during the follow up period of non-cardiac causes (two from an injury and one from a brain malformation). For statistical analyses, the three patients are considered alive with the end of the follow up period the day of their death. An arbitrarily designed combined end point of valvoplasty failure (significant restenosis or insufficiency or need for surgery or death) was observed in 112 patients (41.6\%).

For the whole cohort, the mean (SEM) actuarial probability of survival 14.4 years after the procedure was 0.89 (0.02), of surgery-free survival $0.50(0.08)$, and of reintervention-free survival $0.39(0.07)$. The probabilities were significantly lower in the group of newborns treated in the first four weeks of life than in both the infants treated at the age of 4 weeks to 1 year and the older patients. Differences between the latter two groups were not significant. Actuarial probabilities in the subgroups were as follows.

- Survival: newborns 0.71 (0.05), infants 0.93 (0.03), older patients 0.98 (0.01) (newborns versus both the other groups, $\mathrm{p}<0.001$; infants versus older patients, $\mathrm{p}=0.706)$.

- Surgery-free survival: newborns 0.29 (0.10), infants 0.52 (0.16), older patients $0.65(0.07)$ (newborns versus both the other groups, $\mathrm{p}<0.001$; infants versus older patients, $\mathrm{p}=0.921)$.

- Reintervention-free survival: newborns 0.26 (0.08), infants $0.48(0.15)$, older patients $0.46(0.10)$ (newborns versus both the other groups, $\mathrm{p}<0.001$; infants versus older patients, $\mathrm{p}=0.330$ ) (fig 4 ).

A small z score of the aortic annulus was an independent predictor of restenosis, valvoplasty failure, and death. On the other hand, a large $\mathrm{z}$ score of the aortic annulus was an independent predictor of cusp disruption. A functionally bicuspid aortic valve was an independent predictor of grade 3 

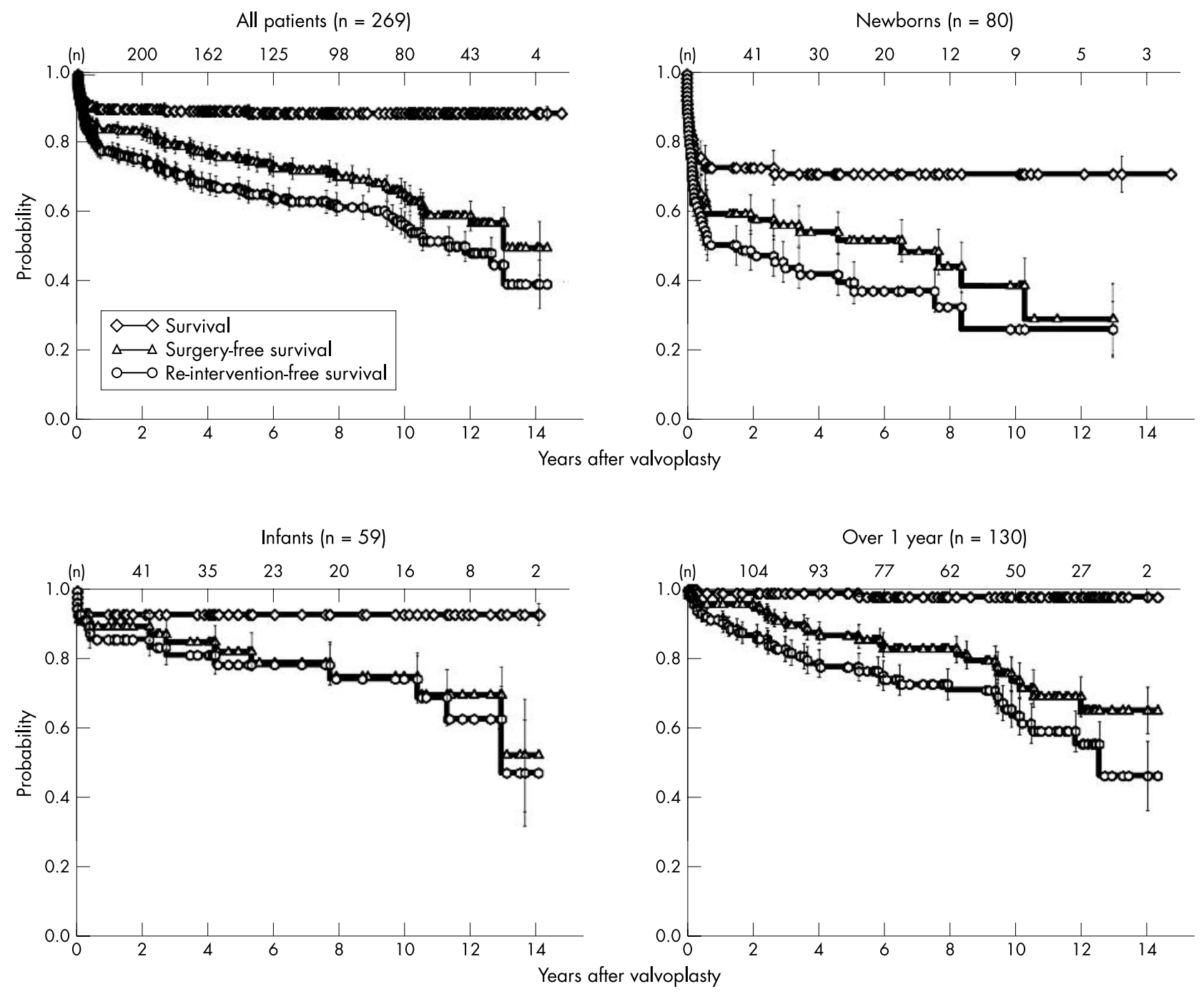

Figure 4 Actuarial probability of survival, surgery-free survival, and reintervention-free survival. Newborns were treated at age $\leqslant 28$ days and infants at 29 days to 1 year. Error bars indicate standard error of the mean.

aortic insufficiency, need for surgery, and valvoplasty failure. Low left ventricular shortening fraction and low sequential number of the valvoplasty were independent predictors of death. A high grade of mitral insufficiency was an independent predictor of valvoplasty failure (table 3). A high grade of mitral insufficiency apparently increased the risk of valvoplasty failure by increasing the risk of surgery (odds ratio $1.64,95 \%$ confidence interval 2.27 to $1.19, \mathrm{p}=0.003$ ). The higher chance of survival with increasing sequential number of the valvoplasty reflects the learning curve.

\section{DISCUSSION}

We present a single institution's experience with 269 consecutive patients with congenital aortic stenosis treated by percutaneous balloon valvoplasty. The institution is a referral centre for 10 million inhabitants and, during the study, in all the referred patients requiring treatment valvoplasty was the initial method used. Ninety five per cent of the patients were followed up for up to 14.8 years after the procedure. The outcome compares with the results of surgical valvotomy or balloon valvoplasty published in the past 10

\begin{tabular}{|lllr|}
\hline Table 3 & Independent risk factors identified by multiple logistic regression & \\
\hline End point & Independent predictor & Odds ratio (95\% CI) & p Value \\
\hline Restenosis & Aortic annulus diameter (z score) & $0.467(0.804$ to 0.369) & 0.002 \\
Aortic insufficiency & Functionally bicuspid valve & $3.107(8.663$ to 1.115$)$ & 0.030 \\
Cusp disruption & Aortic annulus diameter (z score) & $2.238(4.460$ to 1.123$)$ & 0.004 \\
Surgery & Functionally bicuspid valve & $2.572(6.264$ to 1.056$)$ & 0.037 \\
Death & Aortic annulus diameter (z score) & $0.198(0.459$ to 0.086$)$ & $<0.001$ \\
& Left ventricular shortening fraction & $0.432(0.832$ to 0.255$)$ & 0.012 \\
Valvoplasty failure* & Sequential number of valvoplasty & $0.538(0.979$ to 0.296$)$ & 0.043 \\
& Aortic annulus diameter (z score) & $0.551(0.755$ to 0.402$)$ & $<0.001$ \\
& Functionally bicuspid valve & $2.168(4.604$ to 1.021$)$ & 0.044 \\
& Mitral insufficiency & $2.442(5.229$ to 1.141$)$ & 0.021 \\
\hline *Restenosis or significant insufficiency or need for surgery or death. & & \\
\hline
\end{tabular}


years. $^{7-19}$ Similarly to others, ${ }^{2420}$ we have obtained an effective reduction of gradient by valvoplasty and the gradient on average did not increase over the follow up period. In contrast to others, ${ }^{5}$ we have obtained progression of aortic insufficiency from after valvoplasty to the last follow up measurement.

We evaluated a number of factors as possible independent predictors of all the possible unfavourable outcomes of valvoplasty: restenosis, significant aortic insufficiency, cusp disruption, need for surgery, death, and valvoplasty failure. The last end point was especially rigorous and included all the significant residual findings or need for surgery or death. Such an outcome was the case in $42 \%$ of our patients and presumably in the others valvoplasty provided a definitive cure or at least long lasting palliation. Various independent risk factors for valvoplasty outcome identified by the logistic regression have already been reported. In newborns, ${ }^{21}$ the risk factors for death were mitral stenosis, short left ventricle, and aortic annulus diameter $<6 \mathrm{~mm}$. In patients 6 weeks to 20 years old, ${ }^{5}$ the risk factor for early restenosis was age $<3$ years. In a large multi-institutional study of 606 patients aged 1 day to 18 years, ${ }^{22}$ the risk factors for early restenosis were age $<3$ months, high gradient before the valvoplasty, and balloon to annulus ratio $<0.9$. The risk factors for early aortic insufficiency were large annulus, high balloon to annulus ratio, and aortic insufficiency before valvoplasty. Along with the above mentioned factors, unrepaired coarctation of the aorta was identified as the risk factor for an unfavourable result (death or major morbidity). The multiinstitutional study is most similar to ours in methods and patient selection, but determined only the risk factors for immediate outcome. In that study, as opposed to ours, a narrow aortic annulus was not identified as a risk factor for death. The author, however, used absolute annulus diameter (in millimetres) rather than a relative measure such as $\mathrm{z}$ score. The absolute diameter reflects much more the age of patients than the degree of annulus hypoplasia. The author also identified balloon to annulus diameter ratio as a risk factor: a small ratio for restenosis and a large ratio for insufficiency. We could not confirm this finding in our data; our scatter of balloon to annulus ratio, however, was almost twice as narrow (mean (SD) $0.97(0.08)$ as compared to 0.97 (SD 0.15)). In the other study, a large aortic annulus was a risk factor for aortic insufficiency; in ours, the large annulus z score was a predictor of cusp disruption.

Our prime intention was to identify aortic valves that are not suitable for primary surgical treatment with valvoplasty. We found that hypoplastic annuli increase the risk of restenosis and death. Bicuspid aortic valves increased the risk of significant insufficiency and large annuli increased the risk of the cusp disruption. It has been suggested that the higher chance of significant insufficiency in patients with large annuli is a function of increasing valve rigidity with age. ${ }^{23}$ The same authors have documented that in only $31 \%$ of bicuspid aortic valves have the fused cusps not been torn by balloon dilatation and that the outcome was equal regardless of which cusps were fused (right and left coronary or left coronary and non-coronary). In a report of 10 patients treated with balloon valvoplasty during open heart surgery, ${ }^{24}$ in all the tricuspid and anatomically bicuspid valves the effective orifices were enlarged by widening the functioning commissures, but in three of four functionally bicuspid valves, the fused cusp was torn aside the rudimental commissure. Also in our study, the functionally bicuspid aortic valve, but not the anatomically bicuspid ones, increased the risk of late insufficiency and the need for surgery. We presume that unequal rigidity and the different size of the two cusps in the functionally bicuspid valves may be responsible for the difference. Our patients with unicuspid valves had higher mortality than others, but with logistic regression analysis such a valve was not identified as an independent risk factor. To our surprise, neither the reverse doming of the aortic valve nor aortic insufficiency before valvoplasty was identified as a risk factor.

According to our results, valves with hypoplastic annuli and functionally bicuspid valves may be primarily considered for surgery. However, the hypoplastic annuli equally increase the risk of surgical valvotomy, ${ }^{25}{ }^{26}$ and bicuspid valves even with valvotomy increase the risk of aortic insufficiency and the need for valve replacement. ${ }^{27}$ It seems therefore that the outcome of the treatment of congenital aortic stenosis is similar regardless of the method used. Indeed, studies that compared valvoplasty with surgical valvotomy have had almost identical results for these methods. ${ }^{98-32}$ In such a situation, the lower treatment costs and higher patient comfort speak in favour of balloon valvoplasty.

\section{ACKNOWLEDGEMENTS}

The work was supported by grant NA/5963-3, Internal Grant Agency, Ministry of Health, Czech Republic.

\section{Authors' affiliations}

O Reich, P Tax, J Marek, V Rázek, J Gilík, V Tomek, V Chaloupecký, H Bartáková, J Škovránek, Kardiocentrum, University Hospital Motol, Prague, Czech Republic

\section{REFERENCES}

1 Lababidi Z. Aortic balloon valvuloplasty. Am Heart J 1983;106:751-2.

2 Lababidi Z, Wu JR, Walls JT. Percutaneous balloon aortic valvuloplasty: results in 23 patients. Am J Cardiol 1984;53:194-7.

3 Lababidi Z, Weinhaus L. Successful balloon valvuloplasty for neonatal critical aortic stenosis. Am Heart J 1986;1 12:913-6.

4 Rocchini AP, Beekman RH, Ben Shachar G, et al. Balloon aortic valvuloplasty: results of the valvuloplasty and angioplasty of congenital anomalies registry. Am J Cardiol 1990;65:784-9.

5 Galal O, Rao PS, Al Fadley F, et al. Follow-up results of balloon aortic valvuloplasty in children with special reference to causes of late aortic insufficiency. Am Heart J 1997; 133:418-27.

6 Moore $\mathbf{P}$, Egito E, Mowrey $\mathrm{H}$, et al. Midterm results of balloon dilation of congenital aortic stenosis: predictors of success. J Am Coll Cardiol $1996 \cdot 27 \cdot 1257-63$

7 Jindal RC, Saxena A, Juneja R, et al. Long-term results of balloon aortic valvulotomy for congenital aortic stenosis in children and adolescents. J Heart Valve Dis 2000;9:623-8.

8 First T, Škovránek J, Marek J. Normální hodnoty dvourozměrných echokardiografických parametrů u dětí. [Normal values of 2-dimensional echocardiographic parameters in children]. Cesk Pediatr 1992;47:260-4.

9 Gaynor JW, Bull C, Sullivan ID, et al. Late outcome of survivors of intervention for neonatal aortic valve stenosis. Ann Thorac Surg 1995;60:122-5.

10 Cobanoglu A, Dobbs JL. Critical aortic stenosis in the neonate. Results of aortic commissurotomy. Eur J Cardiothorac Surg 1996;10:116-9.

11 Gildein HP, Kleinert S, Weintraub RG, et al. Surgical commissurotomy of the aortic valve: outcome of open valvotomy in neonates with critical aortic stenosis. Am Heart J 1996:131:754-9.

12 Hawkins JA, Minich LL, Shaddy RE, et al. Aortic valve repair and replacement after balloon aortic valvuloplasty in children. Ann Thorac Surg 1996:61:1355-8.

13 Hawkins JA, Minich LL, Tani LY, et al. Late results and reintervention after aortic valvotomy for critical aortic stenosis in neonates and infants. Ann Thorac Surg 1998;65:1758-62.

14 Borghi A, Agnoletti G, Valsecchi O, et al. Aortic balloon dilatation for congenital aortic stenosis: report of 90 cases (1986-98). Heart 1999:82:e10.

15 Chartrand CC, Saro Servando E, Vobecky JS. Long-term results of surgical valvuloplasty for congenital valvar aortic stenosis in children. Ann Thorac Surg 1999:68:1356-9

16 Lambert V, Obreja D, Losay J, et al. Long-term results after valvotomy for congenital aortic valvar stenosis in children. Cardiol Young 2000;10:590-6.

17 Alexiou C, Chen Q, Langley SM, et al. Is there still a place for open surgical valvotomy in the management of aortic stenosis in children? The view from Southampton. Eur J Cardiothorac Surg 2001;20:239-46.

18 Alexiou C, Langley SM, Dalrymple Hay MJ, et al. Open commissurotomy for critical isolated aortic stenosis in neonates. Ann Thorac Surg 2001;71:489-93.

19 Detter C, Fischlein T, Feldmeier C, et al. Aortic valvotomy for congenital valvular aortic stenosis: a 37-year experience. Ann Thorac Surg $2001 ; 71: 1564-71$

20 O'Connor BK, Beekman RH, Rocchini AP, et al. Intermediate-term effectiveness of balloon valvuloplasty for congenital aortic stenosis. A prospective follow-up study. Circulation 1991;84:732-8. 
21 Robinson BV, Brzezinska Rajszys G, Weber HS, et al. Balloon aortic valvotomy through a carotid cutdown in infants with severe aortic stenosis: results of the multi-centric registry. Cardiol Young 2000;10:225-32.

22 McCrindle BW. Independent predictors of immediate results of percutaneous balloon aortic valvotomy in children. Valvuloplasty and Angioplasty of Congenital Anomalies (VACA) Registry Investigators. Am J Cardiol 1996;77:286-93

23 Sholler GF, Keane JF, Perry SB, et al. Balloon dilation of congenital aortic valve stenosis. Results and influence of technical and morphological features on outcome. Circulation 1988:78:351-60.

24 Solymar L, Sudow G, Berggren H, et al. Balloon dilation of stenotic aortic valve in children. An intraoperative study. J Thorac Cardiovasc Surg 1992;104:1709-13.

25 Pelech AN, Dyck JD, Trusler GA, et al. Critical aortic stenosis. Survival and management. J Thorac Cardiovasc Surg 1987;94:510-7.

26 Leung MP, McKay R, Smith A, et al. Critical aortic stenosis in early infancy Anatomic and echocardiographic substrates of successful open valvotomy. J Thorac Cardiovasc Surg 1991;101:526-35.
27 van Son JA, Reddy VM, Black MD, et al. Morphologic determinants favoring surgical aortic valvuloplasty versus pulmonary autograft aortic valve replacement in children. J Thorac Cardiovasc Surg 1996;111:1149-56

28 Gatzoulis MA, Rigby ML, Shinebourne EA, et al. Contemporary results of balloon valvuloplasty and surgical valvotomy for congenital aortic stenosis. Arch Dis Child 1995;73:66-9.

29 Mosca RS, lannettoni MD, Schwartz SM, et al. Critical aortic stenosis in the neonate. A comparison of balloon valvuloplasty and transventricular dilation. J Thorac Cardiovasc Surg 1995; 109:147-54.

30 Justo RN, McCrindle BW, Benson LN, et al. Aortic valve regurgitation after surgical versus percutaneous balloon valvotomy for congenital aortic valve stenosis. Am J Cardiol 1996;77:1332-8.

31 Cowley CG, Dietrich M, Mosca RS, et al. Balloon valvuloplasty versus transventricular dilation for neonatal critical aortic stenosis. Am J Cardiol 2001;87:1125-7, A10.

32 McCrindle BW, Blackstone EH, Williams WG, et al. Are outcomes of surgical versus transcatheter balloon valvotomy equivalent in neonatal critical aortic stenosis? Circulation 2001;104:1152-8.

\section{IMAGES IN CARDIOLOGY}

\section{Acute thrombosis of an extracardiac Fontan conduit}

A 5 year old girl had undergone a Fontan procedure for tricuspid atresia. An extracardiac conduit (16 mm diameter Vascutec) was used to make the inferior vena cava to pulmonary artery connection. Three months post-surgery, and within two weeks of discontinuing coumadin medication and commencing oral aspirin, she presented with acute abdominal pain and shock. Echocardiography and computed tomographic (CT) scans confirmed thrombosis of the inferior vena cava.
At angiography, complete occlusion of the conduit was demonstrated (below left). The thrombus was passed with an 0.035 inch Cordis guidewire. Serial balloon dilation of the conduit was undertaken to re-establish patency. Additional thrombi in the left pulmonary arterial system were also crossed using various guidewire and balloon combinations, and patency of all segmental vessels was established (below centre). Finally, stent implantation was undertaken to relieve residual conduit stenosis, and intravenous streptokinase ( 1000 units/kg/hour for six hours) was administered. Repeat angiography 48 hours later confirmed resolution of all clots, and complete patency of the inferior caval and left pulmonary arterial system (below right). The patient was discharged from hospital after reinstituting oral coumadin treatment.

J A E Kammeraad, N Sreeram j.kammeraad@dz.nl

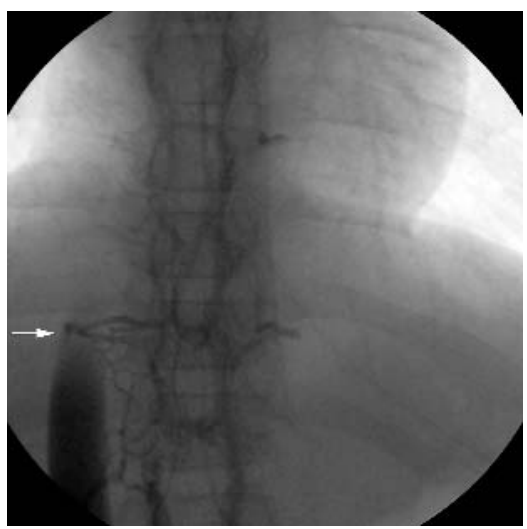

Contrast injection via the femoral vein confirms complete obstruction of the inferior vena cava at its connection to the extracardiac conduit (arrow).
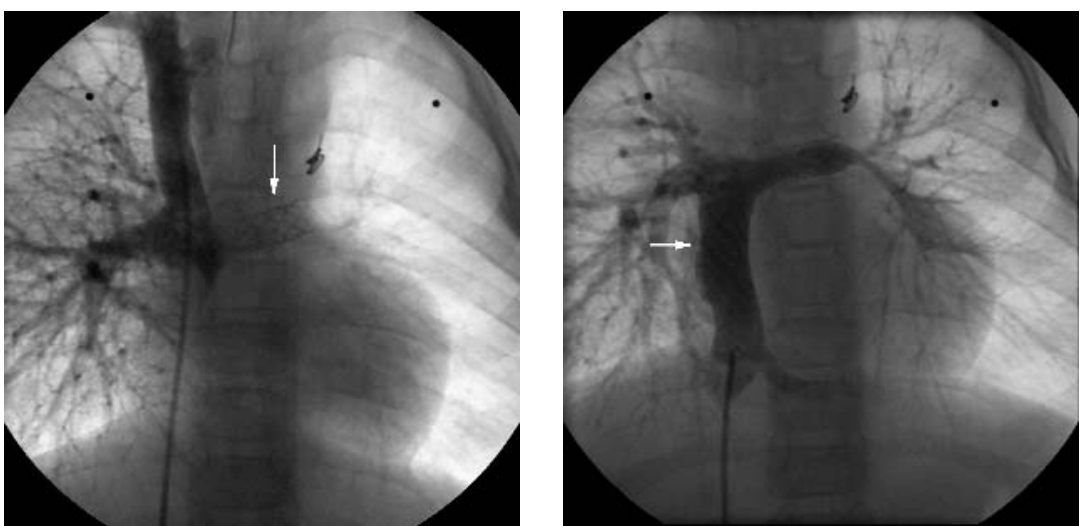

The thrombus has been passed with an end hole catheter. Contrast injection in the superior vena cava confirms complete occlusion of the left pulmonary artery, in which two stents have been implanted (arrow).
A stent has been placed in the Fontan conduit (arrow). The left pulmonary artery system is fully recanalised. 